\title{
sciendo
}

\section{Study on the Factors that Determine the Success of ERP Implementation}

\author{
Wissam EL HAJJ \\ The Bucharest University of Economic Studies, Bucharest, Romania \\ whajj@damana.com \\ Ali SERHAN \\ The Bucharest University of Economic Studies, Bucharest, Romania \\ serhanali333@gmail.com
}

\begin{abstract}
The world boundaries are broken with the advancement of technology and the emergence of digitized industries where economies are connected via the cloud. As a result, effective management of information internally and externally is needed to cope with the quick changes in markets. For a long time, Enterprise Resource Planning (ERP) systems have been used to streamline company processes data, and hierarchy. ERP's are capable of managing big data, integrating business processes and providing effective communication channels within the entire organization. ERP's provide many benefits to businesses if implemented right. However, an alarming 70\% of ERP implementations fail. The failure can very well bankrupt the organization and at the same time affect the vendors very negatively. The aim of this paper is to discuss the critical success factors in ERP implementations from the employees, management, consultants and vendors perspectives. Prior research has identified critical success factors for ERP implementations but none classified them according to the above perspectives (employees, management, consultants and vendors). Surveys were conducted with 60 ERP project participants including senior managers, employees and vendors. A regression analysis was made to investigate the relation between the success of ERP implementations (dependent variable) and the contributions of employees, management, consultants and vendors (independent variables). The study shows that there exists a positive relation between successful ERP implementation and the following: management support, employees' motivation, training, management, vision, and professional consultants. Add to that, the study aids managers and ERP participants to identify the major success factors that must be implemented for the objective of having successful ERP deployment.
\end{abstract}

Keywords: ERP Implementation Success, Critical Success Factors, Strategy, Management.

\section{Introduction}

Globalization and the evolution of information technology impacted the industry, economy, culture and social well-being. In our fast moving and constantly evolving world, and when the necessities and inclinations of clients change, only organizations that are flexible and that quickly adopt to changes survive and maintain their competitive edge.

With the growth of organizations and with the constantly changing laws and regulations (taxes, benefits, etc.), the amount information that an organization produces becomes daunting. To manage this information and to implement the various organization policies, the organization either develops its own in-house software management system, customize it the way they want, or buys a ready developed ERP and still customize it to match the organization needs. Hence ERP is a software that combines all the business departments' functions and facilitates the sharing of information thus eliminating data redundancy and 
enhancing the quality of timely data. If successfully implemented, ERP systems provide many benefits such as cost reduction, improved efficiency, accurate data analysis, and rationalized processes. The change from unintegrated applications to ERP systems is mandatorily governed by the need of increasing competitiveness and sustainable growth of businesses (Dumitru \& Florescu, 2009).

The benefits of ERP systems cannot be attained unless the implementation is successful. Despite the many studies pointing out the ERP implementation critical success factors, an alarming $70 \%$ of ERP implementations still fail. Since, ERP systems provide a coherent business management environment that controls different business operations, its failure can very well destroy the whole organization. Hence, failures encountered in ERP implementations are not only technical but are also related to behavioural, cultural and organizational factors. Businesses adopting ERP systems must understand the point of view of all stakeholders in order to build a cohesive and accepting environment. It is therefore crucial to have a buy-in from all stakeholders before implementing an ERP. Buy-in can be either enforced by the top management or agreed-on, with a preference to agreed-on buy-in.

Based on the literature, the authors classified the success factors in ERP implementations from management, employees, consultants and vendors perspectives. This classification would be beneficial to the concerned parties who are involved in the ERP implementation projects since it will convey the understanding of the different views about the implementation success factors. It will also enable each stakeholder to focus more on the influential factors that lead to a better implementation. In the following section, we overview the previous work on ERP systems implementations and the corresponding success factors.

\section{Literature review \\ ERP systems}

The business environment is changing rapidly and staying competitive is mandatory to survive in the industry. Companies must manage their business processes efficiently to achieve better practices and results. Many researchers have studied ERP systems, their implementation and the success factors. The uncomplicated design of an ERP system is based on a single database, single application and an integrated interface across the entire enterprise where all tasks executed by different departments can be shared (Al-Mashari et al., 2003). ERP systems integrate different areas among the organization (Rajan \& Baral, 2015). Enterprise Resource planning could be a great tool that builds sturdy capabilities, improves performance, supports higher cognitive process, and provides competitive advantage for businesses by providing management with right and updated information (Ahmed et al, 2006). Its main task is to manage all the resources, data, and actions needed to complete business processes such as manufacturing, sales, finance, marketing, human resources and accounting (Nawaz \& Channakeshavalu, 2013).

At its core, ERP enables staff to carry out their work more proficiently by removing hindrances between different units. ERP success provides a worldwide, ongoing perspective of information that can empower organizations to address concerns proactively and drive advancements.

Literature stresses the importance of ERP benefits. However, these benefits cannot be reached unless the ERP is implemented successfully. ERP systems are costly due to their complexity and wideness and their deployment requires a lot more than technical skills; 
hence, their successful implementation rate is low. ERP implementation requires a big budget but its results are not guaranteed (Kazemi et al., 2014). On average, ERP implementation projects take 2.5 times longer than projected, are $178 \%$ over budget, and bring about only $30 \%$ of the agreed benefits (Dezdar, 2012). Another study showed that $60 \%$ to $70 \%$ of ERP projects fail in implementation (Sar and Garg, 2012). A failure in ERP system deployment might very well bring down the whole company regardless how big the company is.

PICBE | 300

\section{Critical success factors}

The question that always arises even nowadays, is that why ERP system implementations fail! One reason is that the execution of ERP is regularly postponed and normally exceeds the underlying budgeted plans (Helo et al., 2008). Another reason is that companies wrongfully think that ERP implementation is a purely technical task and they completely forget the human factors (employees, managers, technical team, leadership, etc.) involved in the process. Picking the appropriate ERP is another important decision which might very well be the recipe of failure before the implementation even starts. The extent of the needed ERP customizations is yet another factor that is mostly ignored or taken lightly. Companies normally either request to customize the deployed ERP to fit their business which might be extremely costly and not accounted for, or they will change their business model following the deployed ERP which again might be the recipe of failure given the resistance-to-change and the new mode of operations. Hence, understanding the critical success factors in ERP implementations is a challenging task for all parties involved in the projects.

Holland and Light (1999) recommended a CSFs research structure with strategic, organisation and technical management scope for ERP implementation. The focus was on applications with slightest divergence from the usual setting along with appropriate customisations of the system to suit the needs.

Teamwork and composition, good coordination and communication, partnership trust, change management culture, organizational culture, user training, education and support, change agents, top management support, business process reengineering and minimum customization, project champion, software development and testing are among the critical factors identified in literature (Nah \& Lau, 2001). The conducted study was based on ten articles, however the authors did not study the perceived importance of the factors across the implementation partners.

Twenty two critical success factors were identified by analyzing 86 questionnaire responses to figure out what are the most important factors through the implementation process (Somers \& Nelson, 2001). The implementation stages identified were initiation, adoption, adaptation, acceptance, routinisation and infusion. What was surprising was that vendors and the use of consultants were not identified as important factors for successful ERP implementation.

Another study reports twenty ERP success factor obtained by analyzing 100 questionnaires distributed to ERP project managers (Colmenares, 2004). The results showed that six out of the twenty factors are highly important and they are: top management support, presence of a champion, project management, best people full time, effective communications and management of expectations. However, the authors did not categorize the critical success factors over the implementation cycle. 
In (Soja, 2006), the following five critical success factors were studied: implementation of participants, top management involvement, project definition, information systems, and project status. The authors relate these factors according to the project type, enterprise size and project duration. However, the success factors were not verified through the project implementation phases to examine their roles on the parties involved. Honest communication and end users' involvement were later added to the critical success factors where the authors in (Huang, 2010) noted that the technical factors are underestimated when compared to the human behavior in ERP implementation. The study concluded its findings by reviewing 524 articles between 1998 and 2007. Another study (Garg, 2010), collected from literature 51 critical success factor of ERP implementation, then narrowed them down to 22 factors. The authors classified the chosen factors among five areas: top management, product selection, project management, team composition, training and education.

The authors in (Heaton et al., 2013) noted that the five important factors for ERP implementation were top management support, communication both internal and external, effective training of end users, effective decision making process and dedicated resources.

In a study done by (Tarhini et al., 2015), fifty one critical success factors were classified according to the stakeholders group. Some of these factors are: end users, top management, IT department, project team, organization, vendor, ERP consultant, employees from different departments and business processes experts. It was also argued that the critical success factors fall into human, organisational, and technical group (Jenko \& Roblek, 2016). The authors deduce that human CSFs is the highest factor that influenced the project implementation success and specifically the competence human factor. The authors in (Altamony, et al., 2016) reported that the ERP critical success factors fall beneath one of five main categories, namely change management, top management support, business process reengineering, vendor support, and user involvement. A study in (Fadelelmoula, 2018) argues that management support, business process re-engineering, project management, technical re-sources, and training represent the top five ranked success factors in ERP implementations.

In can be clearly seen from the above literature survey that various authors select various success factors for ERP implementations. However, there are some common factors that you can always spot in all studies. Based on the commonalities between the various suggested success factors and based on our research, we chose the following 21 success factors as the main factors for ERP successful deployment:

Table1. Critical success factors of successful ERP implementation

\begin{tabular}{|l|l|l|l|}
\hline 1. & Top management support and commitment & 12. & Implementation strategies \\
\hline 2. & Training for different users groups & 13. & Minimal customization of packages \\
\hline 3. & $\begin{array}{l}\text { Clear vision, goals and objectives of the ERP } \\
\text { system }\end{array}$ & 14. & Project management \\
\hline 4. & The use of ERP implementation consultant & 15. & Adequate resources \\
\hline
\end{tabular}




\begin{tabular}{|l|l|l|l|}
\hline 5. & End user involvement & 16. & Interdepartmental communication \\
\hline 6. & Organizational fit for ERP & 17. & Adequate ERP software selection \\
\hline 7. & $\begin{array}{l}\text { Business process re-engineering (BPR) and } \\
\text { process management }\end{array}$ & 18. & Project team competence \\
\hline 8. & Project champion & 19. & Use of vendors' development tools \\
\hline 9. & On-going ERP vendor support & 20. & $\begin{array}{l}\text { Monitoring and evaluation of } \\
\text { performance }\end{array}$ \\
\hline 10. & Team Work & 21. & Organizational Culture \\
\hline 11. & Motivational factors to implement ERP systems & & \\
\hline
\end{tabular}

PICBE $\mid 302$

Source: Authors' own research.

\section{Methodology}

The research work reported in this paper focuses on the issue of defining critical success factors for the implementation of ERP systems. We use a methodology which consist of both: quantitative and qualitative data analysis. We base part of the success factors we suggest on literature review and the other part on a comprehensive questionnaire survey among a number of ERP participants in different organizations.

We categorize the success factors according to four perspectives: management, employees, vendors and consultants. We then formulated a comprehensive survey and distributed it to sixty ERP project participants including employees, managers, vendors and consultants, and finally analyzed the results. The three research questions we aim to address are:

1. Identify which ERP critical success factors mentioned in literature are mostly a concern for ERP participants.

2. Classify the critical success factors according to management, employees, vendors and consultant point of views.

3. Study the impact of managers, employees, vendors and consultants' contribution on the overall success of ERP implementation.

A structured questionnaire is conducted to give the participants the opportunity to express their attitudes and remain anonymous. This encourages the participants to be honest and provide their feedback. Moreover, the use of structured questionnaires enables the researcher to analyze the data collected using SPSS 22. The respondents include employees, managers, consultants and vendors from different sectors: Employees who witnessed the change from legacy to recent ERP systems, managers who supervised the implementation of the ERP projects, consultants who were engaged in ERP applications and vendors of ERP systems.

Respondents were asked to specify their job position in order to check if they are eligible for answering the questionnaire. Likert scale of 1 to 5 was followed to test the agreement of participants with the critical success factors mentioned in literature, categorize the critical 
success factors according to management, consultant, vendor and employee perspectives, and to give their opinion based on real scenarios encountered from their experience. Specifically, the participants would report on the importance of the critical success factors throughout the project cycle implementation. To ensure data validity and reliability of the survey instrument, the questionnaire was reviewed by three experts in the field and the researcher considered their comments seriously and the questionnaire was adjusted to represent reliable results. Moreover, the critical success factors mentioned in the survey are mentioned many times in literature review and categorized according to different criteria. Twelve critical success factors were identified as crucial for successful ERP implementation (Rabaa'i, 2009). Regression analysis was conducted to verify the relation between the dependent variable (ERP successful implementation) and the independent variables (management, employees, vendors and consultants contributions). In order to be able to apply multiple regression, multicollinearity must be checked to exclude the correlated values with the lower level of significance.

Multiple regression between the dependent variable ERP success and the critical independent variables (management, consultants, employees and vendors contributions') proved that there is a significant impact of some of these factors on ERP successful implementation.

The Cronbach's value for each of the critical success factors involved in the study is found to be reliable since each value is above 0.7 as shown in Table 2 which is acceptable as reported in (Hair et al., 2013).

Table 2. Questionnaire reliability

\begin{tabular}{|l|l|}
\hline Critical Success Factors & Cronbach's Alpha \\
\hline Top management support and commitment & 724 \\
\hline Training for different users groups & 726 \\
\hline Clear vision, goals and objectives of the ERP system & 827 \\
\hline The use of ERP implementation consultant & 717 \\
\hline End user involvement & 826 \\
\hline Organizational fit for ERP & 813 \\
\hline Business process re-engineering (BPR) and process management & 822 \\
\hline Project champion & 817 \\
\hline On-going ERP vendor support & 829 \\
\hline Team Work & 734 \\
\hline Motivational factors to implement ERP systems & 828 \\
\hline Implementation strategies & 721 \\
\hline Minimal customization of packages & 822 \\
\hline Project management & 815 \\
\hline Adequate resources & 821 \\
\hline Interdepartmental communication & 823 \\
\hline Adequate ERP software selection & 818 \\
\hline Project team competence & 822 \\
\hline Use of vendors' development tools & 819 \\
\hline Monitoring and evaluation of performance & 801 \\
\hline Organizational culture $\backslash$ Cultural Change/political issues & 805 \\
\hline
\end{tabular}

Source: Authors' own research. 


\section{Results and discussions}

We collected the questionnaires and analyzed the results according to management, vendor, consultant and employees responses. Our aim is to categorize the ERP critical success factors according to their points of views. The means of the success factors under each category signals the importance of which factors mostly contribute to the success of an ERP project implementation.

Table 3 shows that the average mean of employees' responses to all factors is 3.74 . The table gives an indication that employees training, their involvement in implementation across different stages, top management support, motivation, implementation strategies, teamwork, project champion, BPR, organization culture and project champion are among the top factors essential for the success of ERP project. However, all other factors are moderately important except the vendor's support; they did not realize its importance since they are not engaged with any relation with vendors.

Table 3. Descriptive statistics for employees' assessment of ERP critical success factors

\begin{tabular}{|l|l|l|}
\hline ERP success factors & Employees & Rank \\
\hline Training for different users groups & 4.87 & 1 \\
\hline End user involvement & 4.80 & 2 \\
\hline Team Work & 4.67 & 3 \\
\hline Top management support and commitment & 4.60 & 4 \\
\hline Interdepartmental communication & 4.27 & 5 \\
\hline Monitoring and evaluation of performance & 4.20 & 6 \\
\hline Project team competence & 4.13 & 7 \\
\hline Implementation strategies & 4.13 & 8 \\
\hline Business process re-engineering (BPR) and process management & 4.07 & 9 \\
\hline Organizational culture \Cultural Change/political issues & 4.07 & 10 \\
\hline Motivational factors to implement ERP systems & 4.07 & 11 \\
\hline Project champion & 3.80 & 12 \\
\hline Adequate resources & 3.73 & 13 \\
\hline Project management & 3.60 & 14 \\
\hline Adequate ERP software selection & 3.60 & 15 \\
\hline Minimal customization of packages & 3.60 & 16 \\
\hline The use of ERP implementation consultant & 3.60 & 17 \\
\hline Clear vision, goals and objectives of the ERP system & 3.27 & 18 \\
\hline Organizational fit for ERP & 3.13 & 19 \\
\hline On-going ERP vendor support & 2.40 & 20 \\
\hline Use of vendors' development tools & 2.07 & 21 \\
\hline Mean & 3.75 & \\
\hline & $50 u r c e: A 47$ \\
\hline
\end{tabular}

Source: Authors' own research.

Table 4 shows that the average mean of manager's answers is 4.1. The managers' responses stress the importance of the role of management in supporting the success of ERP 
systems implementation throughout the implementation cycle. Moreover, training of users, project management, clear vision and goals, culture, adequate ERP software selection, project champion, end user involvement, motivational factors and interdepartmental communication are the most important for ERP successful project. Vendor support and the use of vendor development tools are not important according to the analysis of their responses.

Table 4. Descriptive statistics for managers' assessment of ERP critical success factors

\begin{tabular}{|l|l|l|}
\hline ERP success factors & Managers & Rank \\
\hline Top management support and commitment & 4.80 & 1 \\
\hline Organizational culture \Cultural Change/political issues & 4.80 & 2 \\
\hline Project management & 4.60 & 3 \\
\hline Team Work & 4.47 & 4 \\
\hline Training for different users groups & 4.40 & 5 \\
\hline Clear vision, goals and objectives of the ERP system & 4.40 & 6 \\
\hline Adequate ERP software selection & 4.33 & 7 \\
\hline Motivational factors to implement ERP systems & 4.33 & 8 \\
\hline Project champion & 4.27 & 9 \\
\hline Interdepartmental communication & 4.20 & 10 \\
\hline End user involvement & 4.13 & 11 \\
\hline Project team competence & 4.07 & 12 \\
\hline Business process re-engineering (BPR) and process management & 4.00 & 13 \\
\hline Implementation strategies & 4.00 & 14 \\
\hline Monitoring and evaluation of performance & 3.87 & 15 \\
\hline The use of ERP implementation consultant & 3.87 & 16 \\
\hline Adequate resources & 3.80 & 17 \\
\hline Minimal customization of packages & 3.73 & 18 \\
\hline Organizational fit for ERP & 3.53 & 19 \\
\hline On-going ERP vendor support & 3.27 & 20 \\
\hline Use of vendors' development tools & 2.93 & 21 \\
\hline Mean & 4.1 & \\
\hline & Source: Authors' own research. \\
\hline
\end{tabular}

The mean of consultant answers is 4.2 as shown in Table 5 . The responses ensure the support of all critical factors as crucial determinants of ERP success except the on-going vendor support, motivational factors and use of vendor's development tools. What was surprising is that they do not qualify motivational factors as important. This may be due to the low size of the sample or because they think that the organization must adopt a culture of recruiting employees that have to obey instructions regardless of the psychological pressures and employees' conditions. 
Table 5. Descriptive statistics for consultants' assessment of ERP critical success factors

\begin{tabular}{|l|l|l|}
\hline ERP success factors & Consultant & Rank \\
\hline The use of ERP implementation consultant & 5.00 & 1 \\
\hline Project management & 4.67 & 2 \\
\hline Top management support and commitment & 4.60 & 3 \\
\hline Project champion & 4.60 & 4 \\
\hline Adequate ERP software selection & 4.53 & 5 \\
\hline Business process re-engineering (BPR) and process management & 4.47 & 6 \\
\hline Training for different users groups & 4.47 & 7 \\
\hline Project team competence & 4.47 & 8 \\
\hline Implementation strategies & 4.47 & 9 \\
\hline Organizational fit for ERP & 4.40 & 10 \\
\hline Interdepartmental communication & 4.33 & 11 \\
\hline End user involvement & 4.27 & 12 \\
\hline Minimal customization of packages & 4.20 & 13 \\
\hline Adequate resources & 4.20 & 14 \\
\hline Organizational culture $\backslash$ Cultural Change/political issues & 4.13 & 15 \\
\hline Monitoring and evaluation of performance & 4.13 & 16 \\
\hline Team Work & 4.13 & 17 \\
\hline Clear vision, goals and objectives of the ERP system & 4.07 & 18 \\
\hline Use of vendors' development tools & 4.00 & 19 \\
\hline Motivational factors to implement ERP systems & 3.40 & 20 \\
\hline On-going ERP vendor support & 2.53 & 21 \\
\hline Mean & 4.08 & \\
\hline & $50 u r c e: A 4 h$ \\
\hline
\end{tabular}

Source: Authors' own research.

The mean of vendors' responses is 4.2 as shown in Table 6. The vendors consider that the use of vendor development tools, vendor support, management support, adequate ERP software selection, training for all users, minimal customization of packages, BPR, project management, adequate resources, project team competence are among the top factors. However, the vendor disregards the organizational fit, motivational factors and monitoring of evaluation and performance.

Table 6. Descriptive statistics for vendors' assessment of ERP critical success factors

\begin{tabular}{|l|l|l|}
\hline ERP success factors & Vendor & Rank \\
\hline On-going ERP vendor support & 4.60 & 1 \\
\hline Interdepartmental communication & 4.53 & 2 \\
\hline Top management support and commitment & 4.40 & 3 \\
\hline Adequate ERP software selection & 4.40 & 4 \\
\hline Use of vendors' development tools & 4.40 & 5 \\
\hline Training for different users groups & 4.33 & 6 \\
\hline
\end{tabular}




\begin{tabular}{|l|l|l|}
\hline Minimal customization of packages & 4.33 & 7 \\
\hline Project management & 4.20 & 8 \\
\hline Business process re-engineering (BPR) and process management & 4.20 & 9 \\
\hline Project team competence & 4.20 & 10 \\
\hline Adequate resources & 4.20 & 11 \\
\hline Team Work & 4.13 & 12 \\
\hline Implementation strategies & 4.13 & 13 \\
\hline Organizational culture $\backslash$ Cultural Change/political issues & 4.00 & 14 \\
\hline Clear vision, goals and objectives of the ERP system & 3.93 & 15 \\
\hline Project champion & 3.93 & 16 \\
\hline The use of ERP implementation consultant & 3.93 & 17 \\
\hline Motivational factors to implement ERP systems & 3.80 & 18 \\
\hline Monitoring and evaluation of performance & 3.67 & 19 \\
\hline End user involvement & 3.47 & 20 \\
\hline Organizational fit for ERP & 3.07 & 21 \\
\hline Mean & 4.08 & \\
\hline
\end{tabular}

Source: Authors' own research.

We then applied regression analysis in order to find answers to the third research question (Methodology section). Whenever regression analysis is considered, there are prerequisite tests to be taken into consideration before running the regression. First, data must be tested if it is normally distributed or not. Second, multicollinearity is a must to investigate if the independent variables are dependent on each other.

Table 7 shows the skewness - kurtosis results. Hair (et al., 2013) indicates that the range between -2.58 and +2.58 with significance level less than 0.01 is a sign of normal distribution. Since all the skewness values fall within the range. Hence, we can conclude that we have a normal distribution.

Table 7. Skewness - Kurtosis test

\begin{tabular}{|l|c|c|}
\hline Critical Success Factors & Skewness & Kurtosis \\
\hline Top management support and commitment & -.419 & -1.889 \\
\hline Training for different users groups & -.409 & -1.129 \\
\hline Team Work & -.625 & -.774 \\
\hline Interdepartmental communication & -.237 & -.607 \\
\hline Project management & -.731 & .456 \\
\hline Organizational culture \Cultural Change/political issues & -1.302 & 2.126 \\
\hline Adequate ERP software selection & -.893 & 1.104 \\
\hline Project team competence & -.222 & -.597 \\
\hline Implementation strategies & -.239 & -.774 \\
\hline Business process re-engineering (BPR) and process management & -.579 & .697 \\
\hline End user involvement & -1.196 & 2.255 \\
\hline
\end{tabular}




\begin{tabular}{|l|c|c|}
\hline Project champion & -.693 & .066 \\
\hline The use of ERP implementation consultant & -.754 & -.085 \\
\hline Adequate resources & -.251 & -.261 \\
\hline Monitoring and evaluation of performance & -.243 & -.160 \\
\hline Minimal customization of packages & -.905 & .401 \\
\hline Clear vision, goals and objectives of the ERP system & -.395 & -.686 \\
\hline Motivational factors to implement ERP systems & -.804 & 1.204 \\
\hline Organizational fit for ERP & -.097 & -.387 \\
\hline Use of vendors' development tools & -.326 & -.724 \\
\hline On-going ERP vendor support & -.042 & -1.043 \\
\hline
\end{tabular}

PICBE | 308

Table 8 shows the collinearity results where the tolerance of all variables are above 0.2 and all VIF values are less than 10 . The variance inflation rate and tolerance are used in order to test the degree or dependency or noninterference of the independent variables with each other. Tolerance value above 0.2 is an indicator that independent variables are not correlated with each other and VIF value less than 10 gives the same interpretation (Hair et al, 2013). The results of the above table reveals the independence of the variables under study.

The statistical results confirms the independence of variables. Consequently, we can apply regression analysis to support the third research question.

H0: There is no significance influence of management, employees, consultants and vendor contribution on the success of ERP implementation.

Table 8. Collinearity Results

\begin{tabular}{|l|c|c|}
\hline \multirow{2}{*}{ Model } & \multicolumn{2}{|c|}{ Collinearity Statistics } \\
\cline { 2 - 3 } & Tolerance & VIF \\
\hline Top management support and commitment & .666 & 1.501 \\
\hline Project management & .547 & 1.830 \\
\hline Business process re-engineering (BPR) and process management & .634 & 1.576 \\
\hline Training for different users groups & .467 & 2.140 \\
\hline End user involvement & .404 & 2.473 \\
\hline Adequate ERP software selection & .406 & 2.461 \\
\hline Organizational culture $\backslash$ Cultural Change/political issues & .655 & 1.527 \\
\hline Clear vision, goals and objectives of the ERP system & .503 & 1.989 \\
\hline Project team competence & & 1.446 \\
\hline Minimal customization of packages & .691 & 1.778 \\
\hline
\end{tabular}

DOI: 10.2478/picbe-2019-0027, pp. 298-312, ISSN 2558-9652| Proceedings of the $13^{\text {th }}$ International Conference on Business Excellence 2019 


\begin{tabular}{|l|c|c|}
\hline Monitoring and evaluation of performance & .704 & 1.421 \\
\hline Project champion & .567 & 1.765 \\
\hline Team Work & .514 & 1.945 \\
\hline On-going ERP vendor support & .449 & 2.227 \\
\hline Organizational fit for ERP & .475 & 2.107 \\
\hline The use of ERP implementation consultant & .625 & 1.600 \\
\hline Motivational factors to implement ERP systems & .589 & 1.699 \\
\hline Implementation strategies & .534 & 1.874 \\
\hline Adequate resources & .421 & 2.374 \\
\hline Interdepartmental communication & .530 & 1.886 \\
\hline Use of vendors' development tools & .405 & 2.472 \\
\hline
\end{tabular}

PICBE | 309

Source: Authors' own research.

Table 9. Regression Summary Results

\begin{tabular}{|l|r|r|r|r|r|r|}
\hline Model & $\mathrm{R}$ & R Square & $\begin{array}{c}\text { Adjusted R } \\
\text { Square }\end{array}$ & $\begin{array}{c}\text { Std. Error of the } \\
\text { Estimate }\end{array}$ & F value & Sig. F Change \\
\hline 1 & .818 & .665 & .638 & 4.855 & 26.649 & .000 \\
\hline
\end{tabular}

Table 10. Multiple regression analysis

\begin{tabular}{|c|c|c|c|c|c|}
\hline \multirow[b]{2}{*}{ Model } & \multicolumn{2}{|c|}{ Unstandardized Coefficients } & \multirow{2}{*}{\begin{tabular}{|l|l|}
$\begin{array}{l}\text { Standardized } \\
\text { Coefficients }\end{array}$ \\
Beta \\
\end{tabular}} & \multirow[b]{2}{*}{ t } & \multirow[b]{2}{*}{ Sig. } \\
\hline & $\mathrm{B}$ & Std. Error & & & \\
\hline (Constant) & 15.960 & 6.784 & & 2.353 & .022 \\
\hline $\begin{array}{l}\text { Management contribution to ERP } \\
\text { Success }\end{array}$ & 249 & .048 & .443 & 5.196 & .000 \\
\hline Employees Contribution to ERP Success & .304 & .050 & .314 & 6.038 & .000 \\
\hline Consultant Contribution to ERP success & 167 & .056 & .156 & 3.001 & .004 \\
\hline Vendor Contribution to ERP Success & .049 & .053 & .078 & .915 & 364 \\
\hline
\end{tabular}

Tables 9 and 10 illustrate that the statistical value $F$ is 26.649 with a level of significance lower than 0.05 which highlights that there is a significant statistical impact of management, employees, vendors and consultants' contributions on the success of ERP implementation. Thus, rejecting the null hypothesis and accepting the alternative hypothesis.

In addition, the Beta value configures that management support effect is positive where the strength of this relationship reaches $44.3 \%$. Depending on the adjusted R-square, the explanatory and predictive value that is the effect of management, employees, vendors and consultant role on the success of ERP system implementation is $63.8 \%$. The results show the significance of management, employees and consultants' role. However, the effect of 
vendor is considered very small. Thus we reject the null hypothesis and accept the alternative hypothesis that shows the positive effect demonstrated by the regression table values.

\section{Conclusion}

Enterprise resource planning systems exist to aid businesses in handling globalized strategies by applying integrated applications among the organization users across all levels. Effective ERP implementation are less about innovation and progressively about individuals and procedures. Hence, resistance to change can take numerous structures and there are various reasons for opposition that are recorded in literature. Top management should proactively manage this issue rather than responsively standing up to it. Earlier research has suggested that the readiness for the usage of ERP must begin early on and a professional dynamic procedure must be received to teach and prepare ERP participants and to minimize the reasons for opposition that might be a part of the organization culture afterwards. In this paper, we reviewed the literature for the critical success factors for ERP implementation and categorized the most successful according to managers, employees, consultants and vendors points of view. Our findings and results support the positive correlation between the ERP success and the contribution of ERP participants, except vendors which revealed a negligible relation. In this regard, a larger sample will improve our understanding of the top ranked CSF in ERP successful implementations and increase the reliability and validity of the research method adopted in this work. This paper aids managers in considering the successful implementation factors when making decisive actions in adopting and implementing ERP systems. This research can provide an analysis framework to help top managers identify the possible difficulties before actually going into the introduction stage, and to make plans for ERP implementation. The present study contributes to the literature as ERPS critical success factors were not disseminated into the management, employees, consultants and vendors

points of view. This academic work could be the beginning of further investigation and analysis into analyzing the critical success factories in specific industries. However there are several limitations for this paper. The sample was not distributed equally among business sectors so further study could be conducted to analyze the ERPS critical success factors in different business types. Thus future research can involve more participants from different companies taking into account the corporation size, expertise level, and different business kinds. It is to be noted that in this study, the size of the organization was not considered or incorporated as part of the survey parameters. Participants' answers may vary according to the enterprise size, objectives and constraints. The work can be further extended to cover more industries and to test the effectiveness and correctness of the relations obtained in this paper.

\section{References}

Ahmed, Z., Zbib, I., Arokiasamy, S., Ramayah, T., \& Chiun, L. M. (2006). Resistance to change and ERP implementation success: The moderating role of change management initiatives. Asian Academy of Management Journal, 11(2), 1-17.

Al-Mashari, M., Al-Mudimigh, A., \& Zairi, M. (2003). Enterprise resource planning: A taxonomy of critical factors. European journal of operational research, 146(2), 352364. 
Altamony, H., Al-Salti, Z., Gharaibeh, A., \& Elyas, T. (2016). The relationship between change management strategy and successful enterprise resource planning (ERP) implementations: A theoretical perspective. International Journal of Business Management and Economic Research, 7(4), 690-703.

Colmenares, L. (2004). Critical success factors of enterprise resource planning systems implementation in Venezuela. AMCIS 2004 Proceedings, 21.

Dezdar, S. (2012). Strategic and tactical factors for successful ERP projects: insights from an Asian country. Management Research Review, 35(11), 1070-1087.

Dumitru, V., \& Florescu, V. (2009). Enterprise resource planning deployment guide. Amfiteatru Economic Journal, 11(25), 213-222.

Fadelelmoula, A. A. (2018). The Effects of the Critical Success Factors for ERP Implementation on the Comprehensive Achievement of the Crucial Roles of Information Systems in the Higher Education Sector. Interdisciplinary Journal of Information, Knowledge, and Management, 13, 021-044.

Fui-Hoon Nah, F., Lee-Shang Lau, J., \& Kuang, J. (2001). Critical factors for successful implementation of enterprise systems. Business process management journal, 7(3), 285-296.

Garg, P. (2010). Critical success factors for enterprise resource planning implementation in Indian retail industry: An exploratory study. ArXiv preprint arXiv: 1006.5749.

Hair, J. F., Black, W. C., Babin, B. J., \& Anderson, R. E. (2013). Multivariate data analysis (7th Ed.). Pearson New International Edition.

Helo, P., Anussornnitisarn, P., \& Phusavat, K. (2008). Expectation and reality in ERP implementation: consultant and solution provider perspective. Industrial Management \& Data Systems, 108(8), 1045-1059.

Holland, C. P., \& Light, B. (1999). A critical success factors model for ERP implementation. IEEE software, (3), 30-36.

Huang, Z. (2010). A compilation research of ERP implementation critical success factors. Issues in Information systems, 11(1), 507-512.

Jenko, A., \& Roblek, M. (2016). A primary human critical success factors model for the ERP system implementation. Organizacija, 49(3), 145-160.

Kazemi, A., Saeidi, S. R., \& Azizmohammadi, M. (2014). Selecting an ERP system using multicriteria decision making method: a goal programming and fuzzy approach. International Journal of Business Information Systems, 16(1), 55-71.

Mengistie, A. A., Heaton, D. P., \& Rainforth, M. (2013). Analysis of the critical success factors for ERP systems implementation in US Federal Offices. In Innovation and Future of Enterprise Information Systems (pp. 183-198). Springer, Berlin, Heidelberg.

Nawaz, M. N., \& Channakeshavalu, K. (2013). The Impact of Enterprise Resource Planning (ERP) Systems Implementation on Business Performance. Asia Pacific Journal of Research, 2(4), 13.

Rabaa'i, A. A., Bandara, W., \& Gable, G. (2009, December). ERP systems in the higher education sector: a descriptive study. In Proceedings of the 20th Australasian Conference on Information Systems (pp. 456-470).

Rajan, C. A., \& Baral, R. (2015). Adoption of ERP system: An empirical study of factors influencing the usage of ERP and its impact on end user. IIMB Management Review, 27(2), 105-117.

Sar, A., \& Garg, P. (2012). Analysis of critical failure factors in ERP implementation: an Indian experience. International Journal of Business Information Systems, 11(3), 360-378. 
Seymour, L., Makanya, W., \& Berrangé, S. (2007, April). End-users' acceptance of enterprise resource planning systems: An investigation of antecedents. In Proceedings of the 6th annual ISOnEworld conference (pp. 1-22).

Soja, P. (2006). Success factors in ERP systems implementations: lessons from practice. Journal of enterprise information management, 19(4), 418-433.

Somers, T. M., \& Nelson, K. (2001, January). The impact of critical success factors across the stages of enterprise resource planning implementations. In System Sciences, 2001. Proceedings of the 34th Annual Hawaii International Conference on (pp. 10-pp). IEEE.

Tarhini, A., Ammar, H., \& Tarhini, T. (2015). Analysis of the critical success factors for enterprise resource planning implementation from stakeholders' perspective: A systematic review. International Business Research, 8(4), 25. 